\title{
Comparison between Laser Hemorrhoidoplasty Procedure and Conventional Open Surgical Hemorrhoidectomy
}

\author{
Wesam Nuri Yahya*, Doaa Omar Refaat, Waleed Ahmed AbdElhady, Walid Abdelmawla Elsayed \\ General Surgery Department, Faculty of Medicine, Zagazig University, Egypt \\ *Corresponding author: Wesam N. Y. Ahlasa, Mobile: (+2)01201221764, Email: ahlasawesam@gmail.com
}

\begin{abstract}
Background: Hemorrhoids are a very common anorectal condition defined as the symptomatic enlargement and distal displacement of the normal anal cushions.

Objective: The present study aimed to compare between laser hemorrhoidoplasty and conventional open surgical hemorrhoidectomy in treatment of the hemorrhoidal diseases.

Patients and methods: This study included 30 patients with symptomatizing hemorrhoidal diseases. They were divided into two groups: 15 patients underwent open method (MMH) and 15 patients underwent laser method (LHP). They were admitted to General Surgery Department, Faculty of Medicine, Zagazig University Hospitals with symptomatic hemorrhoidal diseases. Full history, clinical examination and pre- and post-operative assessment were performed.

Results: The mean age was distributed as $36.03 \pm 7.32$ in the MMH group and $35.73 \pm 8.39$ years in the LHP group with no significant difference between both groups. The mean operative time was distributed as $29.53 \pm 4.05$ and 14.60 \pm 3.13 minutes for MMH and LHP groups respectively. The mean hospital stay for MMH group was $36.25 \pm 6.58$ hours and $7.85 \pm 2.11$ hours for LHP, MMH group significantly associated with longer hospital stay. MMH group was significantly associated with more bleeding at $1^{\text {st }}$ and $2^{\text {nd }}$ week but no bleeding founded after $2^{\text {nd }}$ week at both groups.

Conclusion: laser hemorrhoidoplasty (LHP) technique for the management of hemorrhoids was, with shorter operative time, less postoperative pain, shorter hospital stay, and less postoperative complications than open surgical hemorrhoidectomy.
\end{abstract}

Keywords: Laser hemorrhoidoplasty, VAS, Open surgical hemorrhoidectomy

\section{INTRODUCTION}

Hemorrhoids are a very common anorectal condition defined as the symptomatic enlargement and distal displacement of the normal anal cushions. They affect millions of people around the world, and represent a major medical and socioeconomic problem (1). The highest incidence rate of the disease is found among patients aged between 45 and 65 years, while the incidence rate of the disease decrease after 65 years of age. Men are more often affected than women (2).

Bleeding, is the principal and earliest symptom of hemorrhoids. The nature of the bleeding is characteristically separate from the motion and is seen either on the paper for wiping or as a fresh splash in the pan. Very rarely, the bleeding may be sufficient to cause anemia. Pain is not commonly associated with the bleeding and its presence should make the clinician alert to the possibility of another diagnosis; however, pain may result from congestion of pile masses below a hypertonic sphincter ${ }^{(3)}$. The patients also may complain of prolapse and anal irritation, which may occur as a result of mucus secretion from the caudally displaced rectal mucosa, minor leakage through a now imperfect anal seal or difficulties in cleaning after defecation because of the irregularity of the anal verge ${ }^{(4)}$.

There are many treatments of hemorrhoids varying from medications and band ligation to stapled hemorrhoidopexy, laser photocoagulation, sclerotherapy, Doppler-guided artery ligation, and finally surgery ${ }^{(5)}$.

Postoperative pain is the most common trouble with this surgery. The other early complications are urinary retention, hemorrhage and abscess formation. The long-term complications include anal fissure, anal stenosis, stool incontinence, perianal fistula, and recurrence of the disease. These drawbacks have led to the introduction of diode laser treatment. Intrahemorrhoidal laser coagulation or laser hemorrhoidoplasty (LHP) was first described in $2009^{(2)}$ and reported in larger series of patients ${ }^{(\mathbf{6})}$, giving rise to numerous advantages such as easy and efficient application, and noninvasive nontoxic painless nature, in addition to reduction of the need of pharmaceutical drugs, drug interactions, and their side effects ${ }^{(7)}$.

The aim of the present study was to find the better management and improving outcome of the patients of hemorrhoids.

\section{PATIENTS AND METHODS}

This prospective comparative clinical study was carried out on 30 patients with grade 2 and grade 3 hemorrhoidal disease admitted to General Surgery Department, Faculty of Medicine, Zagazig University Hospitals with symptomatizing hemorrhoidal diseases. The study took place from June 2020 to March 2021. 
Patients were divided randomly into: Group I (Conventional Open Surgical Hemorrhoidectomy method): Fifteen patients underwent open conventional hemorrhoidectomy by Milligan-Morgan Hemorrhoidectomy technique (MMH), and Group II (laser method): Fifteen patients were operated upon with Laser Hemorrhoidoplasty (LHP) "laser method".

Inclusion criteria: Patients with symptomatic 2 nd or 3rd degree of hemorrhoids not responding to medical treatment in age above 21 years old of both sexes.

Exclusion criteria: Patients with associated anorectal diseases (e.g. fistula, abscess, rectal carcinoma, inflammatory bowel disease, etc...), $1^{\text {st }}$ or $4^{\text {th }}$ degree of hemorrhoids, pregnancy and patients unfit for surgery.

\section{Operative Assessment:}

Full history was taken from patients including name, age, and sex. Proper clinical examination was carried out. Routine preoperative investigations were performed include complete blood count, random blood sugar, liver function tests, kidney function tests, and coagulation profile.

All operations were performed under spinal anesthesia, with the patient in the supine lithotomy position. A standardized procedure was followed for performing the surgery in each group by the same surgical team.

\section{Group I: Open surgical hemorrhoidectomy:}

A V-shaped incision was made in the skin surrounding the base of the hemorrhoid. Then dissection in the submucous space was done by cautery to strip the hemorrhoid from its bed. The dissection was continued in the cranial direction up to the pedicle. The pedicle was then ligated with a $2 / 0$ vicryl suture, and the distal part of the hemorrhoid was excised. Same steps were carried out regarding the other hemorrhoids, leaving a skin bridge between them to avoid anal stenosis. The wounds were left open, light dressing with topical gentamicin cream and a gauze was left in the anal canal. The time of the operation was recorded in minutes. Patients were discharged within 24 hours in case of no postoperative complications and the patient urinate without difficulties.

\section{Group B: Laser hemorrhoidoplasty:}

The laser procedure was performed using the (lasotronix laser Poland) and start with proper clinical examination PR in lithotomy position. A dedicated disposable proctoscope $(23 \mathrm{~mm}$ in diameter) was inserted in the anal canal. The procedure started via small incision to the skin in about $(1 \mathrm{~cm})$ distance from the anal edge. At the base of each hemorrhoid the laser fiber was introduced into the hemorrhoidal plexus taking into consideration that the fiber should be parallel to the anal canal to avoid injury or burn of the mucosa or internal sphincter. Using a $980 \mathrm{~nm}$ diode laser, before laser shooting, we must wear antilaser glasses. The depth of shrinkage can be controlled by the power and duration of the laser beam. Through the optic fiber, laser shots were generated at a power of $7.5 \mathrm{~W}$ with duration of $3 \mathrm{~s}$ each shot followed by a pause of $0.5 \mathrm{~s}$ causing shrinkage of tissues up to the depth of $5 \mathrm{~mm}$. After finishing each hemorrhoid, an ice finger was introduced intra-anally for $0.5-1 \mathrm{~min}$ to decrease the heat effect. Patients were discharged from 6-8 hour after surgical operation, in case of no postoperative complications and the patient urinate without difficulties.

\section{Postoperative care:}

Spinal anesthesia usually takes a few hours to wear off. The pack inserted in the rectum after surgery was removed before discharge. Postoperative analgesia in the form of diclofenac sodium $100 \mathrm{mg}$ was prescribed daily on need not more than three times per day. Metronidazole $500 \mathrm{mg}$ tab three times per day for one week prescribed to prevent infections and to reduce the pain. A gentamicin cream was prescribed on need up to three times daily. Prescribes stool softeners and laxatives (duphalac).

\section{Follow up:}

All patients were followed up postoperatively at 1, 2, 4, 6 weeks and after 6 months after the operation in the outpatient clinic. Regarding postoperative pain was considered as the main outcome and was evaluated with the visual analogue scale (VAS 0-10), where $0-1=$ no pain, 1.1-3= low pain intensity, 3.1-7= pain of medium intensity, $7.1-9=$ pain of high intensity, and $9.1-10=$ strong at $1,2,4,6$ weeks and after 6 months.

\section{Ethical approval:}

The study was approved by the Ethical Committee of Zagazig, Faculty of Medicine. An informed consent was obtained from every patient in this research. Every patient received an explanation for the purpose of the study.

All given data were used for the current medical research only. This work has been carried out in accordance with The Code of Ethics of the World Medical Association (Declaration of Helsinki) for studies involving humans.

\section{Statistical analysis}

Data were then imported into Statistical Package for the Social Sciences (SPSS version 20.0) software for analysis. According to the type of data, qualitative were represented as number and percentage, while quantitative continues group was represent by mean \pm $\mathrm{SD}$. The following tests were used to test differences for significance: difference and association of qualitative variable by Chi square test (X2). Differences between quantitative independent groups by $\mathrm{t}$ test or Mann Whitney. P value was set at $\leq 0.05$ for significant results $\&<0.001$ for highly significant results. 


\section{RESULTS}

Age was distributed as $36.03 \pm 7.32$ and $35.73 \pm$ 8.39 years with no significant difference between groups. Also, there was no significant difference regarding sex distribution as the groups were nearly matched and male represented the majority of both groups. The age range was 22-47 years (Table 1).

Regarding degree of the hemorrhoids distribution, there was no significant difference or association among the studied patients (Table 2).

Operation time was distributed as $29.53 \pm 4.05$ minutes (range 33.58-25.48) and $14.60 \pm 3.13$ minutes (range 11.47-17.73) respectively between open and laser groups. Open group was significantly longer than laser group (Table 3). Open group significantly associated with longer hospital stay (Table 4).

Concerning bleeding, open group was significantly associated with more bleeding at 1 st and 2nd week but no bleeding founded after 2 nd week at both groups (Table 5).

There was a highly significant difference between the two groups regarding pain till the 6th week and analgesia used in open group significantly higher (Table 6).

Table (1): Age and sex distribution between studied groups

\begin{tabular}{|c|c|c|c|c|c|c|}
\hline & & & Open Group & Laser Group & $t / X^{2}$ & $\mathbf{P}$ \\
\hline \multicolumn{3}{|c|}{ Age } & $\begin{array}{c}36.03 \pm 7.32 \\
(23-47)\end{array}$ & $\begin{array}{c}35.73 \pm 8.39 \\
(22-45)\end{array}$ & \multirow[t]{3}{*}{0.339} & \multirow[t]{3}{*}{0.690} \\
\hline \multirow[t]{4}{*}{ Sex } & Female & $\mathbf{N}$ & 5 & 4 & & \\
\hline & & $\%$ & 33.3\% & $26.7 \%$ & & \\
\hline & Male & $\mathbf{N}$ & 10 & 11 & \multirow[t]{2}{*}{0.15} & 0.69 \\
\hline & & $\%$ & $66.7 \%$ & 73.3\% & & \\
\hline \multirow{2}{*}{\multicolumn{2}{|c|}{ Total }} & $\mathbf{N}$ & 15 & 15 & & \\
\hline & & $\%$ & $100.0 \%$ & $100.0 \%$ & & \\
\hline
\end{tabular}

Table (2): degree of the hemorrhoids distribution between studied groups

\begin{tabular}{|c|c|c|c|c|c|}
\hline & & \multicolumn{2}{|c|}{$\overline{~ G r o u p ~}$} & \multirow[t]{2}{*}{$\overline{X^{2}}$} & \multirow[t]{2}{*}{$\mathbf{P}$} \\
\hline & & Open Group & Laser Group & & \\
\hline \multirow{2}{*}{$\begin{array}{l}2^{\text {nd }} \text { degree of } \\
\text { hemorrhoids }\end{array}$} & $\mathbf{N}$ & 5 & 4 & \multirow{4}{*}{0.0} & \multirow{4}{*}{1.0} \\
\hline & $\%$ & 33.3\% & $26.7 \%$ & & \\
\hline \multirow{2}{*}{$\begin{array}{l}3^{\text {rd }} \text { degree of } \\
\text { hemorrhoids }\end{array}$} & $\mathbf{N}$ & 10 & 11 & & \\
\hline & $\%$ & $66.7 \%$ & $73.3 \%$ & & \\
\hline \multirow[t]{2}{*}{ Total } & $\mathbf{N}$ & 15 & 15 & & \\
\hline & $\%$ & $100.0 \%$ & $100.0 \%$ & & \\
\hline
\end{tabular}

Table (3): operation duration distribution between studied groups

\begin{tabular}{|l|c|c|l|l|}
\hline & Open Group & Laser Group & t & P \\
\hline $\begin{array}{l}\text { Operative time } \\
\text { (minute) }\end{array}$ & $29.53 \pm 4.05$ & $14.60 \pm 3.13$ & 11.230 & $0.00 * *$ \\
\hline
\end{tabular}

Table (4): Hospital stay distribution between studied groups

\begin{tabular}{|l|c|c|l|l|}
\hline & Open Group & Laser Group & t & P \\
\hline Hospital stay/H & $36.25 \pm 6.58$ & $7.85 \pm 2.11$ & 17.123 & $0.00 * *$ \\
\hline
\end{tabular}


Table (5): Bleeding distribution between studied groups at different stations of follow up

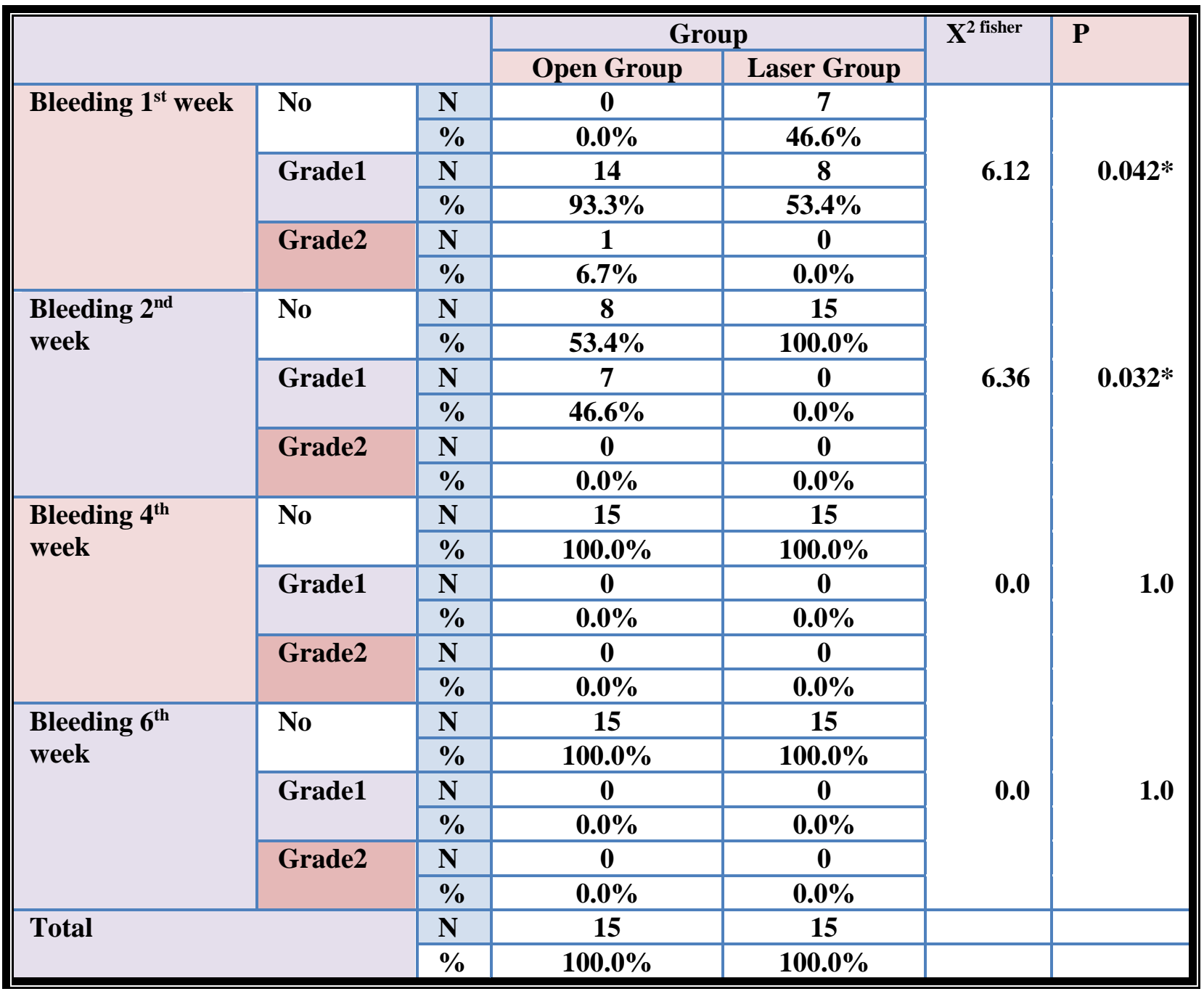

Table (6): Pain assessed by VAS and analgesia doses distribution between studied groups at different stations of follow up

\begin{tabular}{|c|c|c|c|c|}
\hline & Open Group & Laser Group & $\begin{array}{l}\text { Mann } \\
\text { Whitney }\end{array}$ & $\overline{\mathbf{P}}$ \\
\hline VAS_DAY_1 & $9.53 \pm 0.51$ & $5.93 \pm 0.79$ & 15.699 & $0.00 * *$ \\
\hline VAS_WEEK_1 & $6.53 \pm 0.51$ & $3.66 \pm 0.72$ & 12.874 & $0.00 * *$ \\
\hline VAS_WEEKS_2 & $4.0 \pm 0.0$ & $0.0 \pm 0.0$ & 8.139 & $0.00 * *$ \\
\hline VAS_WEEKS_4 & $2.0 \pm 0.0$ & $0.0 \pm 0.0$ & 4.396 & $0.00 * *$ \\
\hline VAS_WEEKS_6 & $1.0 \pm 0.0$ & $0.0 \pm 0.0$ & 1.147 & 0.211 \\
\hline VAS_MONTHS_6 & $0.0 \pm 0.0$ & $0.0 \pm 0.0$ & $\mathbf{0 . 0 0}$ & 1.00 \\
\hline Dose of analgesia & $650.0 \pm 80.58$ & $210.5 \pm 35.6$ & 10.26 & $0.00 * *$ \\
\hline
\end{tabular}

\section{DISCUSSION}

Hemorrhoidal disease is ranked much higher than the rectum and colon diseases. The presence of hemorrhoidal disease is evaluated to be between $2.9 \%-$ $27.9 \%$ among the worldwide population and $4 \%$ are symptomatic. One third of the total number of patients ask for medical advice ${ }^{(8)}$.

This prospective comparative clinical study was carried out on 30 patients with grade 2 and grade 3 hemorrhoidal disease admitted to General Surgery
Department, Faculty of Medicine, Zagazig University Hospitals with symptomatizing hemorrhoidal diseases.

In our study, the age range was (22-47) and the mean age was distributed as $36.03 \pm 7.32$ years in the MMH group and $35.73 \pm 8.39$ years in the LHP group with no significant difference between both groups. Also, there were no significant differences regarding sex distribution as males represented the majority of both groups. Eskandaros and Darwish ${ }^{(9)}$ reported that the age among MMH group had a mean of $41 \pm 8.8$ years, and LHP group had a mean of $40.8 \pm 8.8$ years, 
with no significant difference among both groups. 85 $(70.83 \%)$ were males and $35(29.17 \%)$ were females, with no significant difference among the groups. Alsisy et al. ${ }^{(7)}$ revealed that the age among MMH group had a mean of $33.67 \pm 10.22$ and LHP group had a mean of $34.73 \pm 10.17$ with no significant difference among the three groups. Males were $18(60 \%)$ and female were 12 (40\%) with no significant difference among the groups.

In our study, the mean operative time was distributed as $29.53 \pm 4.05$ minutes (range 33.58-25.48) and14.60 \pm 3.13 minutes (range 11.47-17.73) respectively between the open and laser group, and the open group had significantly longer time than the laser group. This is in agreement with Naderan et al. ${ }^{(10)}$ where MMH group had $33.1 \pm 7.3 \mathrm{~min}$ vs. LHP group that $15.6 \pm 5.26 \mathrm{~min}$. The operative time was also significantly shorter in the laser group than $\mathrm{MMH}$ group. Also, Maluku et al. ${ }^{(8)}$ stated that the procedure time for LHP was 15.94 min vs. 26.76 min for open surgery, which is in agreement with our results.

In our study, the mean hospital stay for MMH group was $36.25 \pm 6.58$ hours, while, in LHP was 7.85 \pm 2.11 hour, $\mathrm{MMH}$ group significantly associated with longer hospital stay. Eskandaros and Darwish (9) stated that the mean hospital stay in group MM was 2.1 \pm 0.6 days and in group LHP was $0.7 \pm 0.3$ day with highly significant difference between both groups. Besides, Voigtsberger et al. ${ }^{(11)}$ revealed hospitalization lasted for 3 days.

Our study found that $\mathrm{MMH}$ group was significantly associated with more bleeding at $1^{\text {st }}$ and $2^{\text {nd }}$ week but no bleeding founded after $2^{\text {nd }}$ week at both groups. Mohammed et al. ${ }^{\text {(1) }}$ found that post-laser hemorrhoidoplasty, $89.8 \%$ of patients developed mild bleeding in form of spotting after defecation. Only $20.6 \%$ kept spotting till 5th day. $1 \%$ had moderate to severe bleeding, 2 cases (out of 500). Post-traditional hemorrhoidectomy, $97.6 \%$ of patients developed mild bleeding, only $2.4 \%$ of cases had moderate to severe bleeding after the operation, while $60.6 \%$ of cases kept spotting till 5th post-operative days. Bleeding post-laser hemorrhoidoplasty significantly lower than posttraditional hemorrhoidectomy. Eskandaros and Darwish ${ }^{(9)}$ found that patients in group MMH week 1 $(67.5 \%)$ week $2(37.5 \%)$ week 3(30.0\%) week 4(2.5\%) of patients had bleeding and in group LHP week 1 (7.5 $\%$ ) of patients had bleeding, which was statistically considered highly significant.

In our study, from week 1 until 6th-week open group was significantly higher regarding pain, but there was no significant difference between both groups after the 6th week. Naderan et al. ${ }^{(10)}$ conducted that postoperative pain was significantly lower in the laser group 12 to $24 \mathrm{hr}$ after the procedure. In addition, Maloku et al. ${ }^{(8)}$ compared MMH and LHP and found significant difference between them regarding pain with mush less pain and early relief of pain in the laser group.

\section{CONCLUSION}

Laser hemorrhoidoplasty (LHP) technique for the management of hemorrhoids was associated with shorter operative time, less postoperative pain, shorter hospital stay, and less postoperative complications than open surgical hemorrhoidectomy.

\section{Financial support and sponsorship: Nil. Conflict of interest: Nil.}

\section{REFERENCES}

1. Mohammed A, Al-Sultani D, Janabi H (2019): A comparative study between laser hemorrhoidoplasty procedure and conventional hemorrhoidectomy. Journal of University of Babylon, Pure and Applied Sciences, 27 (1): 69-86.

2. Plapler H, Hage R, Duarte J et al. (2009): A new method for hemorrhoid surgery: intrahemorrhoidal diode laser, does it work? Photomed Laser Surg., 27 (5): 819 823.

3. Thomson W (2009): The nature of haemorrhoids. Br J Surg., 62:542

4. Salfi R (2009): A new technique for ambulantory hemorrhoidal treatment Doppler-guided laser photocoagulation of hemorrhoidal arteries. Coloproctology, 31: 99-103.

5. Giamundo P, De Angelis M, Mereu A (2020): Hemorrhoid laser procedure with suture-pexy (HeLPexx): a novel effective procedure to treat hemorrhoidal disease. Techniques in Coloproctology, 24 (2): 199-205.

6. Karahaliloglu A (2010): Laser hemorrhoidoplasty- a new surgical procedure for the treatment of advanced hemorrhoidal illness. Coloproctology, 32: 116-123.

7. Alsisy A, Alkhateep Y, Salem I (2019): Comparative study between intrahemorrhoidal diode laser treatment and Milligan-Morgan hemorrhoidectomy. Menoufia Medical Journal, 32 (2): 560.

8. Maloku H, Lazović R, Terziqi H (2019): Laser hemorrhoidoplasty versus Milligan-Morgan hemorrhoidectomy: Short-term outcome. Vojnosanit Pregl., 76: 8-12.

9. Eskandaros M, Darwish A (2020): Comparative study between Milligan-Morgan hemorrhoidectomy, stapled hemorrhoidectomy, and laser hemorrhoidoplasty in patients with third degree hemorrhoids: A prospective study. The Egyptian Journal of Surgery, 39: 352-363.

10. Naderan M, Shoar S, Nazari M et al. (2017): A randomized controlled trial comparing laser intrahemorrhoidal coagulation and Milligan-Morgan hemorrhoidectomy. J Invest Surg., 30: 325-331.

11. Voigtsberger A, Popovicova L, Bauer G et al. (2016): Stapled hemorrhoidopexy: functional results, recurrence rate, and prognostic factors in a single center analysis. International Journal of Colorectal Disease, 31 (1): 35-39. 